International Journal on Information Sciences and Computing, Vol. 4, No.2, July 2010

\title{
IMPROVED TOTAL PRODUCTIVE MAINTENANCE USING LEAN PRINCIPLES IN AIRCRAFT MANUFACTURING AND MAINTENANCE
}

\author{
Kolanjiappan. S. ${ }^{1} \operatorname{Maran}^{2} \mathrm{~K}$. \\ 1 Research Scholar, Sathyabama University, Chennai. India \\ 2 Professor \& Director, Sri Sairam Institute of Management Studies, Chennai India
}

\begin{abstract}
In the recent years the interest on improving aircraft manufacturing and maintenance methods to face the changing environments has become a prime research area. Total productive maintenance (TPM) development emerged as a result of these studies. TPM is an initiative for optimizing the reliability and effectiveness of manufacturing equipment. TPM is a team based proactive maintenance and involves at every level and function in the organization, from top executive to the shop floor. Parallel to this, Lean manufacturing introduced a massive paradigm shifting to production processes in different industries. Later lean aircraft maintenance development, a derived process from Lean manufacturing emerged. Despite its main focus on defect minimization, it was considered another facet of TPM. In this study we emphasize the key difference between the two practices and examine the possible improvements to the TPM from lean principles that ultimately would lead to a hybrid practice.
\end{abstract}

Key Words: Kanban, Muda - Waste, Value stream

\section{INTRODUCTION}

A primary requirement for a manufacturing plant is (production) equipment reliability. Maintenance practices, in turn, have become a primary determinant of equipment reliability. The reactive style of maintenance practiced during the greatest part of the history of maintenance must be replaced with proactive ([pro -+ reactive]: i.e. acting in anticipation of future problems, needs, or changes) maintenance practices in order to achieve the levels of equipment reliability necessary to sustain manufacturing goals and objectives. There are "Fundamental Laws of Manufacturing Maintenance". These laws are based on a fundamental maintenance program that is the very foundation of lean maintenance. It could be appropriately termed as Total Productive Maintenance or TPM. TPM is formulated to achieve maximum equipment reliability in support of production. Organizations are hard pressed to enhance their capability to create value for customers and improve the cost effectiveness of their operations. Maintenance, as a critical support function in businesses with significant investments in physical assets, plays a major role in meeting this tall order. A consensus of a number of surveys indicates that within the manufacturing industry, maintenance spending ranges between 14 and $25 \%$ of the total factory operating costs. Within process industries in general, and aviation industries specifically, the maintenance and operations departments are nearly always the largest with each comprising between 38\% and $43 \%$ of total staffing. Attaining the right mix of physical assets and making the best use of those already in place to meet business needs are the ways maintenance can contribute to improving competitiveness of physical asset, capital-intensive organizations.

Lean thinking is important because it can reduce defect rates to 1 per million units [1]. It has been shown beyond question to at least double the productivity of both manufacturing and service operations [2]. It also significantly reduces the time taken to deliver new products while substantially reducing cost [3]. The evidence from all over the world: Toyota (Japan), Porsche (Germany) and Pratt \& Whitney (USA), shows that lean techniques produce significant levels of improvement [4]. After a long spell of recession, the aircraft industry has gained significant stride due to growing domestic demands. According to the news 'voice in America' in the next few years, India expects to buy more than 300 passenger planes for its domestic airlines, while the Indian Air Force plans to buy 126 new warplanes. Aviation analysts expect India to spend as much as 35-billion dollars on new planes in the next 20 years.

At the same time, India is also exploring the possibility of joint ventures with foreign aircraft companies. India is expected to emerge as the fastest growing Maintenance Repair and Overhaul (MRO) market over the next 10 years. MRO spending is 
estimated to rise from merely $\$ 440$ million in calendar year 2007 to $\$ 1.2$ billion in 2017, exhibiting a CAGR (compounded annual growth rate) of $11.8 \%$," says a September 2008 report by audit and consultancy firm Ernst and Young India Pvt. Ltd. "Further, the Indian MRO industry is expected to have the potential to service a fleet of 1,000 commercial and 500 general aviation aircraft by 2020," [5]. Globally, MRO is a $\$ 40$ billion industry and is expected to grow at a CAGR of $5 \%$ to $\$ 55$ billion by 2015 , it said. In this scenario, the Indian aircraft industries have witnessed substantial improvements in recent years. In this situation, the authors strongly suggest that Lean maintenance transformation is essential for Indian aircraft industry.

In this direction, the implementation of lean philosophy is methodically examined and recommended to identify the areas generating waste. Further various industrial wastes have been documented to facilitate the optimization of the operating conditions in a minimal investment. Although the underlining theory works on a broader domain; this paper will be circumscribed to the shop floor by only taking into account the limitations of space. This research addresses the implementation of lean philosophy on the maintenance shop floor. The prime objective is to develop different strategies to eliminate waste by means of work-in progress (WIP), motion time, set-up time, lead time, defects, etc. considering the economical needs of the problem. In this research, we demonstrate how a value stream map can be integrated to visualize a better picture of the various forms of non-value-added activities present in the system, thus reducing the problem of waste.

In this research we identified the Key factors of LEAN practices to improve the TPM practices. Then we examined the overlapping areas in between these two process paradigms and focused on the other process areas for the improvements. In that one main objective we identified was that injecting Key Success Factors (KSF) of LEAN method would improve the existing practice of maintenance which could be easily utilized without putting much effort to TPM practice in sustainable manner. The presentation of this paper is as follows. In section 2, we will discuss the background literature in related with this study. In section 3 , we discuss the identified problem in brief. Thereafter in the section 4 the experiment methodology has been emphasized. Even though the results in section 5, does not contain any numerical figures of the results, it further describes the importance of the selected result parameters to preserve the clarity of the paper. Finally section 6, the analysis section is explained as how the analysis is done based on the collected results from this study which strongly facilitates the conclusion of this study.

\section{BACKGROUND}

As mentioned, this study is to evaluate the successfulness of the enhanced Total Production Maintenance process by introducing Lean practices. For that the most important task is to identify the improvable areas in TPM practices, as well as the applicable techniques from the Lean methods. To strengthen the study we referred large number of literature on TPM process, Lean practices and related areas. Following is a comprehensive study of the literature we used for this study.

\subsection{Total Productive Maintenance}

TPM is an initiative for optimizing the reliability and effectiveness of manufacturing equipment. TPM is team-based, proactive maintenance and involves every level and function in the organization, from top executives to the shop floor. TPM addresses the entire production system life cycle and builds a solid, shop-floor-based system to prevent all losses. TPM objectives include the elimination of all accidents, defects and breakdowns.

\subsection{Lean Practice}

LEAN practice was developed in Japanese automobile production companies. This is also known as Toyota Production System. Taiichi Ohno was considered as the father of this practice. Once confined to the automotive industry, lean principles are becoming standard operating procedure in many industries today. Simple reason for that is when implemented with a good performance management system, lean principles have a proven track record of operational and strategic success, which ultimately translates into increased value to the end customer. Lean is a principle driven, tool based philosophy that focus on eliminating waste so that all activities/steps add value from customer's perspective. Specifications of value, identification of all the steps in the value stream, smooth flow, pull value, and pursue perfection are the five principles in LEAN practice [6]. Figure 1 shows these principles. Throughout the LEAN practice it targets to reduce the unnecessary overhead activities and outputs as well as 
wastes from the production line. With this prime norm LEAN method only activates necessary activities at the latest time they could be performed with minimal/zero defects. LEAN practice is composite with unique methodologies to perform the operational activities. Kanban (Pull) production system is one important method. In that method, throughout the production lines one can schedule the process efficiently, and activates the flow using signaling to each others related to the workflow. In 1953 Toyota applied this logic in their main plant machine shop [7].

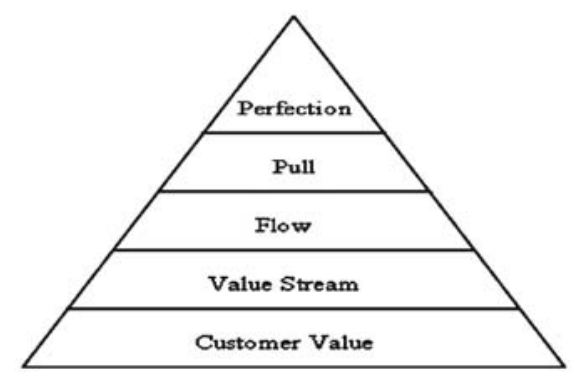

Fig. 1. Lean Principles for success

\subsection{Lean Maintenance Development}

Table 1: Corresponding, Maintenance wastes to the Manufacturing Wastes Identified in Lean Maintenance development

\begin{tabular}{|l|l|}
\hline \multicolumn{1}{|c|}{$\begin{array}{c}\text { Manufacturing } \\
\text { waste }\end{array}$} & \multicolumn{1}{|c|}{ Maintenance waste } \\
\hline Overproduction & Over maintenance \\
\hline Inventory & $\begin{array}{l}\text { Over stocking of spares, } \\
\text { consumables, obsolete parts and } \\
\text { large inventories of infrequently } \\
\text { used and/or expensive or limited } \\
\text { shelf life items }\end{array}$ \\
\hline $\begin{array}{l}\text { Extra } \\
\text { processing steps }\end{array}$ & Duplication of maintenance work \\
\hline Motions & $\begin{array}{l}\text { Workers movement, Movement } \\
\text { of test equipments and testers }\end{array}$ \\
\hline Defects & $\begin{array}{l}\text { Instances of reworking, redoing } \\
\text { and repeatedly repairing an item } \\
\text { due to failure to identify root } \\
\text { cause of a failure. }\end{array}$ \\
\hline
\end{tabular}

\begin{tabular}{|l|l|}
\hline $\begin{array}{c}\text { Manufacturing } \\
\text { waste }\end{array}$ & \multicolumn{1}{|c|}{ Maintenance waste } \\
\hline Waiting & $\begin{array}{l}\text { When maintenance personnel } \\
\text { are forced to sit idly for parts to } \\
\text { come, or wait for some other } \\
\text { event }\end{array}$ \\
\hline Transportation & $\begin{array}{l}\text { Tools stored far from the job or } \\
\text { task-at-hand, common or } \\
\text { repetitive use of parts that have } \\
\text { not been preassembled or kitted, } \\
\text { documentation that must be } \\
\text { found and work orders for } \\
\text { machines that are not available } \\
\text { for shutdown are common } \\
\text { causes. Each activity requires } \\
\text { transportation. }\end{array}$ \\
\hline
\end{tabular}

Maintenance is not subordinate to production rather it is a supportive service. "Lean Maintenance" is basically reliability and reduced need for maintenance troubleshooting and repairs. Lean Maintenance comes from protecting against the real causes of equipment downtime -- not just their symptoms. Any maintenance engineer or manager can begin Lean Maintenance by protecting automation, electronics, hydraulics and computer-controlled equipment from the real cause of malfunctions, failures, and downtime-chronic stress discussed above. Circuit board failures, hydraulic system failures and other malfunctions are only symptoms, not the underlying cause of unscheduled equipment downtime. Over 25 years of experience, Amemco has learned to move client companies through implementation of Lean Maintenance in 30 days (TPM), rather than taking years.

Lean Maintenance is maximizing uptime, yield, productivity, and profitability. The key objective of Lean Maintenance is to give your company the near $100 \%$ equipment uptime and reliability it demands while cutting your maintenance expense, often by $50 \%$ or more. This is done by systematically surveying or analyzing each machine and control system to determine which basic stresses are affecting each machine, over time, and laying out a scheme to protect each machine, computer, or control system from the stresses to which it is subject. This certainly includes but goes far beyond the TPM oil change, filter change preventive maintenance (PM) procedures given in the 
maintenance manual. You must first understand the three categories of downtime:

1. Downtime from Operator or Programmer Error

2. Downtime from inadequate PM procedure or performance.

3. Downtime from chronic wear \& stress to circuit boards, hydraulic components and other system components. Stresses such as: a. Heat b. Vibration c. Oxidation \& Corrosion d. Dirt build-up e. Electrical voltage transients and current surges f. Hydraulic contaminations of dirt, water \& acids, etc.

In early 1990s maintenance professionals tried to adopt the LEAN production principles to maintenance development. However, the objectives were mainly targeted to defect minimization of the product. In this context LEAN Maintenance Development identified the correspondent maintenance wastes to the seven wastes defined in the LEAN manufacturing process. It is shown in the Table 1. [8]

\section{PROBLEM}

Having discussed about the characteristics of the two processes, we are about to formulate the research problem for this study. Most organization that implemented TPM failed to achieve the results that were anticipated. TPM was seen as a cost-cutting venture and was never sponsored or committed to by upper management. The required TPM investment, as well as the return, is very high. TPM cannot be applied to unreliable equipment; therefore the company must initially bear the additional expense of restoring equipment to its proper condition and educating personnel about the equipment. Team activities are basic to TPM. Teams at top management, middle management and shop floor level carryout TPM activities. Each type of team has its own objectives and part to play.

On the other hand, if we consider the LEAN practices, it again cannot be taken as a complete process model for the maintenance development. The main reason is that it provides only the behavioral approach for a maintenance success. Specially, it focuses on waste minimization and quality improvements. This may not cover the entire maintenance process with both technical parts and managerial parts.

\section{METHODOLOGY}

The research data collection is based on actual monitoring of the selected activities on aircraft maintenance. In order to preserve the fairness between experiment samples as much as possible, we used second year students of aeronautical engineering in aircraft assembly and maintenance of Cessena-152 and Piper aircrafts. These two aircrafts are newly bought in dismantled condition from England for educational purpose. Ten activities (each activity has two similar components, like starboard wing and port wing, starboard aileron and port aileron etc.) were selected in the aircraft maintenance and allotted to two groups members per each activity. All of these activities were started from the same time and having same resources for their activities. Among the two groups, one group called A group has completed the job by using TPM practice. Another group B was thought with LEAN practices, principles and application of LEAN tools in aircraft maintenance activities. Group B also carried out similar job as group A. Group B activities were the experiment sample in which the enhanced TPM practice with LEAN method was used as process model.

\subsection{Research Hypothesis}

The research hypothesis considered for this study is as follows:

Null hypothesis: TPM maintenance processes of an aircraft cannot be improved using LEAN practice techniques.

Alternative hypothesis: TPM maintenance processes of an aircraft can be improved using LEAN practice techniques.

In order to evaluate this hypothesis we selected the statistical analysis of collected data with reasonable amount of sample size.

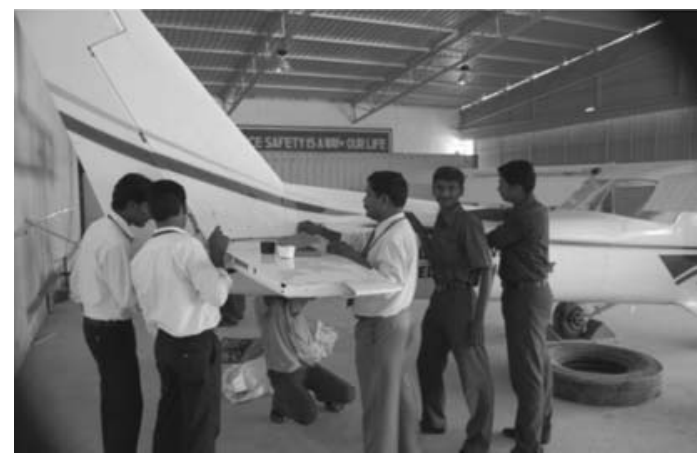

Fig. 1. Group A 


\subsection{Experiment Method}

As mentioned in the problem section this study aimed to examine the success of applying LEAN practice to improve TPM practice in aircraft maintenance. For all selected activities we gave required level of competency on practicing TPM process. We used hands on labs, knowledge sharing sessions to make all the 40 students at a reasonable and similar competency level for this experiment. Then we separated one group who were practicing hybrid TPM process. They were thought with Lean practicing methods and selected lean techniques to practice along with TPM process.

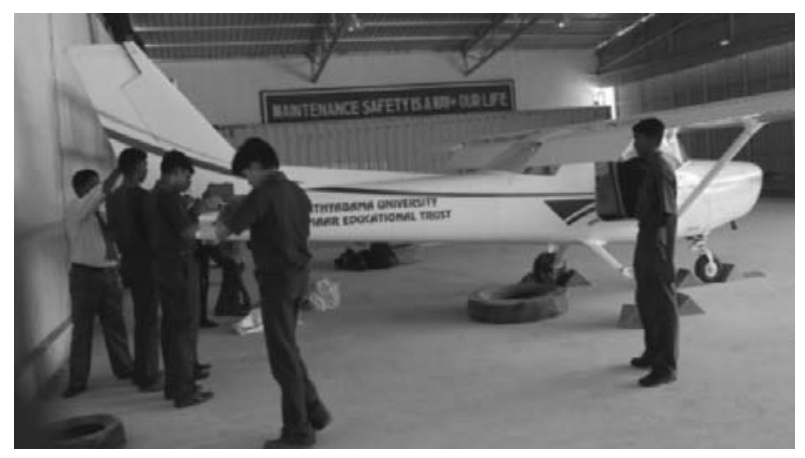

Fig. 2. Group B

\subsection{Experiment Limitations}

This research experiment is also suffered from one of the main concerns with TPM process, the people factor. Altogether there are 40 students used for this experiment. Among these 40 participants there can be slight different competencies from each other for performing the aircraft maintenance activities. However we think that since their average exposure to the aircraft maintenance activities, technical knowledge and resource, this may be the best set of samples that one could find for this kind of experiment. If we select the sample from industry, it would have been a collection with higher variance value for people capabilities.

Another problem we faced was that all these ten activities are on different location of an aircraft. However the activity scopes were examined by a panel of expert scholars at the beginning and ensured that none of the activities are neither above nor below to the required scopes. Also since we are considering only a time interval in the activities, entire activity loads or work amount will not affect to the study.

\section{RESULTS AND DISCUSSIONS}

One important obstacle that faced when deciding what types of measures to be taken was that identifying most suitable performance measures to track the aircraft maintenance enhancements and the progress in this context. LEAN practices with production systems have their own performance parameters and their matrixes. However, since this is a study of evaluating certain improved practices of aircraft maintenance activities; we had to focus on performance parameters and matrixes which are defined for the aircraft maintenance.

\subsection{Measurement Parameter}

Table. 2 shows selected parameters for the performance measures. These data are collected for each day of the activities and per activity basis. One important fact to mention here is that we calculated overall efficiency of the work and given weights by considering man-hour, job perfection, job planning and documentation of the work by both the groups. Weights of the activity are tabulated in the following table.

Table 2. Aircraft maintenance parameters and their results, collected data.

\begin{tabular}{|l|c|c|}
\hline \multicolumn{1}{|c|}{ Job } & $\begin{array}{c}\text { Weights of } \\
\text { jobs efficiency } \\
\text { gained by A } \\
\text {-TPM group }\end{array}$ & $\begin{array}{c}\text { Weights of } \\
\text { jobs efficiency } \\
\text { gained by B- } \\
\text { LEAN group }\end{array}$ \\
\hline Wing fitment & 7 & 10 \\
\hline Stabilizer fitment & 6 & 9 \\
\hline Elevator fitment & 5 & 8 \\
\hline Flap fitment & 4 & 7 \\
\hline Aileron fitment & 6 & 9 \\
\hline Wheel fitment & 3 & 10 \\
\hline $\begin{array}{l}\text { Bleeding of } \\
\text { brake unit }\end{array}$ & 8 & 6 \\
\hline Seat fitment & 4 & 8 \\
\hline $\begin{array}{l}\text { Undercarriage } \\
\text { fitment }\end{array}$ & 7 & 9 \\
\hline Paneling & 2 & 9 \\
\hline Total weights & 52 & 85 \\
\hline
\end{tabular}


The number of defects fixed is important to understand the difference between the paradigms in the context of quality enhancements to the developed applications. It is expected to have higher number of defect fixation rate for the new method over the TPM practice during the first couple of time periods. Expected work and actual work levels are taken to identity the facilitation levels of the two examined process models for achieving the objectives related to its schedule. All these performance attributes are measured as a count during the examined time period along with their respected work amount in efficiency of the work. The efficiency of the work measure is very important to identify the different work load portions with respect to selected parameters in the conventional TPM practice and the improved method.

\section{ANALYSIS}

Statistical techniques have been used to perform the hypothesis tests based on the collected data. This weighted sum was found in per group basis. Considering the efficiency of the work on each category and the usefulness to the final completion we have decided to have weights for the activities. With these weights we found the weighted sums of 10 values per group in the two groups A - TPM group and B Improved TPM practice group.

\subsection{Hypothesis - Using efficiency of the work}

As the statistical analysis we used test statistic " $f$ " method to test the hypothesis using the weights of the efficiency of the job values. In that test, for group A we found the mean $X_{A}=5.2$ and the group $B$ we found the mean $X_{B}=8.5$ and $\sigma^{2} s 1=2.19$ and $\sigma^{2} s 2=1.45$. From the average efficiency values it is clear that improved TPM practice capable of producing more than the TPM practice. With the ' $\mathrm{t}$ ' test we observed the t-value as -3.988 which is less than -2.101 and therefore we reject the Null hypothesis $\left(H_{0}\right)$ with $95 \%$ confidence level which implies that the TPM process activities can be improved by applying LEAN practice.

\subsection{Value stream analysis:}

Value stream analysis (VSA) is just one tool from the lean tool-kit, which can help to implement the five lean principles. The primary focus of VSA is on identifying the value stream for a product. However, it also enables waste to be exposed and opportunities for making better use of flow and pull to be identified. VSA entails examining all of the actions required to take a product or service through the flow of the production process and bring it into the hands of the customer. Each of these actions is analyzed from the point of view of whether it adds value in the eyes of the customer. Non-value add activities are often referred to by the Japanese term 'muda' (waste), and fall into two categories:

(a) Those activities which create no value but are currently required and cannot be eliminated yet (type one 'muda'),

(b) Those activities which do not create value and can be eliminated immediately (type two 'muda').

Once the type two 'muda' has been eliminated, opportunities should be sought to reduce the type one 'muda' through the use of new practices or new technologies. Although VSA is a good method for eliminating waste at the local level, its main strength is in the improvement opportunities that can be identified at the more generic level, for example by improving communication and process flow between departments or by eliminating double-handling.

Data was collected by observing students (both the group) doing their jobs. Each step was broken down into a series of activities, the time taken for each activity was recorded, and each activity was given a designation to indicate whether it added value. Value-add activities were designated as 'operation', while non-value add activities were categorized as 'delay' (including queuing and rework), 'transport' (of material or information) or 'inspection'. Supporting information was also collected, such as numbers of people involved, any discussion required, use of equipment and systems, and problems encountered. This analysis enabled improvement opportunities specific to each process area to be identified.

Figure 3 shows the break-down for the group A team. In this case, $20 \%$ of the total time is spent on value-add activities, $25 \%$ of the total time is spent on activities necessary behind the scenes of work and $55 \%$ is on non-value add activities. 


\section{Group -A}

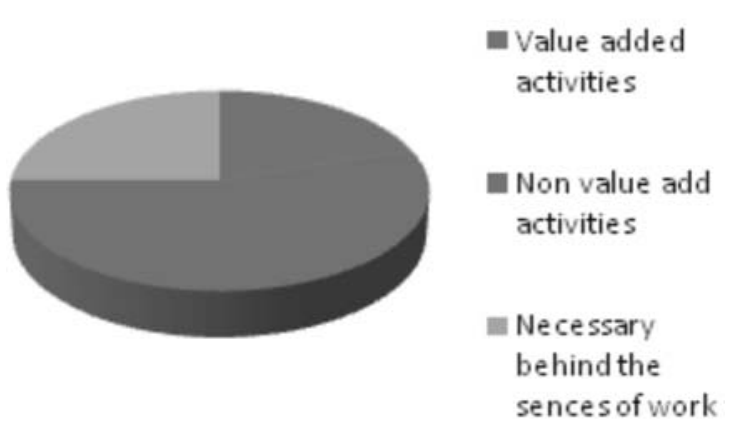

Fig. 3. Value added and Non-value added activities of A-group

Figure 4 shows the break-down for the group $B$ (improved) team. In this case, $28 \%$ of the total time is spent on value-add Activities, $20 \%$ of the total time is spent on activities necessary behind the scenes of work and $52 \%$ is on non-value add activities.

\section{Group-B}

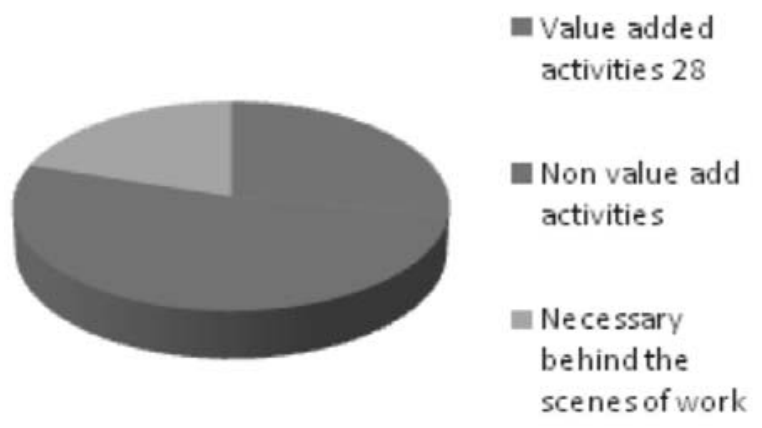

Fig. 4. Value added and Non-value added activities of B-group

However, far too many jobs do not proceed down this route for a variety of reasons, including delays, poor internal communications and need for rework. The VSA data enabled the most common reasons for such failure to be diagnosed, so that the most significant improvement areas could be identified.

\subsection{Defect rate behavior}

Apart from the hypothesis testing, we also analyzed the defect fixing rate for the two samples through the examined time period. A defect was classified as an unexpected or erroneous behavior of a selected component which has been already tested successfully and committed to the function. With that respect, malfunctioning of component during functional test were not considered as defects.

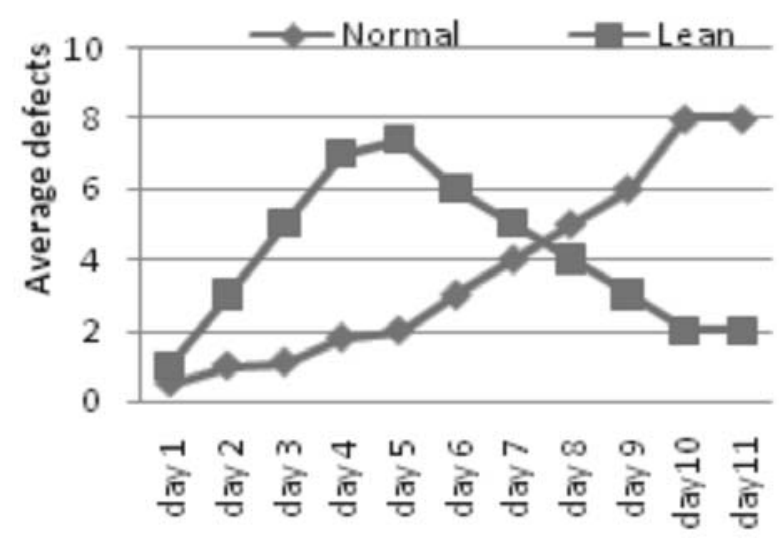

Fig. 5. Average defect rates in the time period for the two samples

A significant 9difference in defect rate pattern between the two samples was observed during the experiment time as shown in figure.5. A higher rate for LEAN sample at the early stages of development was due to that their autonomous and value perfection norms with the development. On the other hand, the TPM group did not find many defects at the early stages, since they did not pay much attention to the perfection of what they develop, while they were doing it. At the later stages this situation swapped between the two samples and LEAN practice seemed to have a stable minimal defect rate, where as the TPM practice experienced a high and varying defects rate. A possible reason was that unfixed hidden defects in components from early developments would cause emerging defects once they integrated each other. Importantly having lesser defects in later stages was very essential for the stability of the function and to be aligned with the function schedule. Also defects emerged in later stages were relatively expensive to fix. Based on the available information we concluded that applying LEAN principles did help stabilize the TPM development phase especially in later stages of the phase.

\section{CONCLUSION}

In this research we tried to identify possible improvable parts in the TPM maintenance development process and how the LEAN development practice could be used to overcome those. Then we examined those possible improvements and analyzed the collected data. Statistically we have seen that our argument of LEAN principles can be used to improve the TPM paradigm, 
is correct. Moreover since the objective of this study was not to invent any new maintenance development paradigm but to improve the TPM method, it is justifiable to say that the new hybrid paradigm can be used without putting much additional effort and cost to the TPM practice based on our observations in this study. Importantly another vital factor of this research is that even though it deals with two similar maintenance process models, the enhanced hybrid TPM practice does not contain any redundant process activities, which may be visible with both TPM practice and the LEAN practice. With all this regard we believe that, this study will create a significant paradigm shift to the TPM maintenance development process.

\section{REFERENCES}

[1] Schonberger, 1986, p. 221. Womack J.P

[2] D.T. 'Lean Thinking' Simon and Schuster (1996) Womack 1990; Ohno, 1988

[3] Womack and Jones, 'Lean Thinking' 1997.

[4] The report, authored by Kuljith Singh, partner, and Asha Katyal, associate director at E\&Y.

[5] Womack J.P and D.T. (1996) 'Lean Thinking', Simon and Schuster.

[6] Ohno T., 1988 Toyota production system, Beyond large scale production, productivity press pp.25-29

[7] "Lean Maintenance" - Reduce cost, improve quality and increase market share by Ricky Smith and Bruce Hawkins.

[8] Womack J.P and D.T. (1996) 'Lean Thinking', Simon and Schuster.

[9] Womack J P and Jones D T: (1996) 'Lean thinking', Simon and Schuster.

[10] Adams E K and Willetts K J: (1996) 'The lean communications provider', McGraw-Hill.

[11] Ohno T., 1988 Toyota production system, Beyond large scale production, productivity press pp.25-29

[12] "Lean Maintenance" - Reduce cost, improve quality and increase market share by Ricky Smith and Bruce Hawkins

[13] Poppendieck M., 2002 Principles of LEAN thinking, Onward-1 $17^{\text {th }}$ Annual ACM Conference on Object-Oriented Programming, Sys. Languages and Applications, Washington.
[14] Smalley, (2005) Lean and the Law of Unintended Consequences, Super factory www.lean.org.

[15] Womack J.P, Jones DT, Roos D (1990) The machine that changed the world, Machmillan, New York.

[16] Lee-Mortimer A (2006) A Lean route to manufacturing survival, Assem Autom 26(4); 265-272

[17] Holweg M (2007). The genealogy of lean production. J.Oper Manag 25(2);420-437 doi;10,1016 jj.jom.2006.04.001

[18] Morgan J and J.K. Liker. 2006 'The Toyota product Development system: Integrating people, process and Technology, New York. Productivity press.

[19] Rother. M and Shook J: Learning to see: Value stream mapping to add value and Eliminate MUDA Brookline: Lean enterprise Institute, 1999.

[20] Schuh, G: 2007, Lean Innovation- Die Handlungsanleitung in $4^{\text {th }}$ Lean management summitAachener management Tage, $G$ Schuh and $B$ Wiegend, Ed, Aahen: Apprimus-Verlag.

[21] Adams E.K. and Willetts K.J. (1996) 'The lean communication provider McGraw-Hill.

[22] Wilson P, Dell.L and Anderson G ' 1993, Root cause analysis - a tool for total quality management.' ASQC Quality press.

[23] Mayhew A J and Stockton DJ, (1998) 'Cost-reduced cable delivery for the $21^{\text {st }}$ century', B.T Technol J, 16, No.4 PP22-100.

[24] Krause.D \& Temple V 1998, Maintenance management In: 'Water system operation and maintenance workshop, Session notes, Denver, Co.

S.Kolanjiappan area of interest

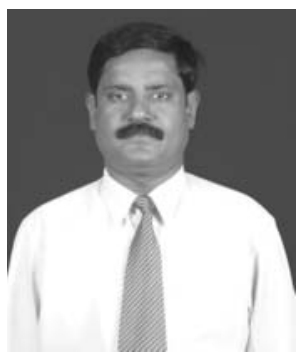

is reduction of wastages and adding values to the maintenance operation of an aircraft. He has 20 years of experience in maintenance of fighter aircrafts in Indian Air Force, one year of experience in production of aircraft in aircraft division HAL, Nasik and six years of experience in teaching both in Hindustan College of Engineering and Sathyabama University. He was commended by Air officer commanding, Eastern Air Command Indian Air Force for rectifying fuel snag in one of the fighter aircraft. 